\title{
A ADOLESCENTE E O FILHO DESNUTRIDO: CUIDADO CULTURAL
}

\author{
THE ADOLESCENT MOTHER'S UNDERNOURISHED CHILD: CULTURAL CARE
}

\author{
Mirna Albuquerque Frota ${ }^{1}$ \\ Maria Grasiela Teixeira Barroso² \\ Zulene Ma. de Vasconcelos Varela ${ }^{3}$
}

\begin{abstract}
RESUMO: Aborda o contexto cultural familiar da adolescente, mãe de criança desnutrida, utilizando-se o método etnográfico para refletir sobre o cuidado dessas mães para com seus filhos. Percebe-se que as mães adolescentes aceitam de familiares e vizinhos orientação sobre o que é melhor para o cuidado do filho. Concluise pela necessidade de um trabalho educativo que contextualize o cuidado da criança desnutrida em seus aspectos socio-culturais.
\end{abstract}

PALAVRAS CHAVE: Enfermagem; Cultura da família; Criança desnutrida; Mãe-adolescente.

\section{INTRODUÇÃO}

Acompanhando mães adolescentes de crianças desnutridas no Instituto de Prevenção à Desnutrição e à Excepcionalidade (IPREDE), em Fortaleza-C eará-B rasil, foi possível conviver com famílias que expressavam em seu cotidiano indícios de uma série de crenças e mitos relacionados ao binômio saúde - doença. Chamava a atenção a carga de responsabilidade que, na família, as adolescentes assumiam pelo fato de terem filhos. A transição da infância para a fase adulta, caracterizada por conflitos, mudança no corpo, novas amizades, experiências sexuais, dentre outros, complica-se quando a garota se torna mãe e tem de cuidar do próprio filho sem nenhuma experiência anterior. Nestes casos, o risco de desnutrição infantil é uma realidade.

Abordando mães com crianças hospitalizadas, durante as orientações relacionadas ao cuidar do filho, percebemos forte influência da família em seu modo de agir. É válido ressaltar que a maior parte mora com a mãe ou com a sogra, tendo sido abandonadas pelo pai da criança. A mãe adolescente, nesta nova conjuntura, absorve os valores e o modo de vida da família que a abriga. Com isso, o cuidar do filho desnutrido vem a ser um aprendizado constante de crenças e ensinamentos que passam de geração em geração, caracterizando 0 que conhecemos como o cuidado cultural.

$\mathrm{Na}$ verdade, se observa que a realidade vivida pela mãe adolescente, seus valores, suas crenças, sua cultura, estão enraizados no cotidiano de sua família, dificultando, muitas vezes, a aceitação e confiança em orientações recebidas no contato com o serviço de saúde. Para Elsen et al (1994, p.20), o mundo das famílias tem se mostrado complexo, e seu processo de viver único, porém compartilhado com outras famílias e grupos. A família, como cliente, detém certas características que para a enfermagem ainda se configuram como um desafio.

Na realidade, vê-se a importância de se respeitar o cuidado empírico que, segundo os valores das mães, é o melhor para o filho, porém, através de princípios educativos em que as mães discutam seu modo de pensar, sua visão de mundo e manifestem suas sugestões, como também as de seus familiares, provoca-se uma reflexão quanto à prática do cuidar (Freire,1987) podendo-se, assim, acreditar na possibilidade de transformação das práticas adotadas anteriormente pela mãe, que possam ter contribuído para a instalação ou agravamento da desnutrição do filho.

O cuidado do filho, mesmo sendo fundado na cultura, resultante da experiência acumulada das gerações anteriores, deve ser visto pelos profissionais de saúde como algo que pode sofrer influência de um processo

\footnotetext{
Doutoranda em Enfermagem. Universidade Federal do Ceará.

Prof. - Emérita. Titular do Departamento de Enfermagem da Universidade Federal do Ceará

Prof. a Titular do Departamento de Enfermagem da Universidade Federal do Ceará.
} 
educativo em que se toma conhecimento das opções para o cuidar, mas que, ao mesmo tempo dá possibilidade ao sujeito de escolher o caminho próprio em relação ao cuidar do filho desnutrido.

Os clientes portadores da desnutrição infantil tendem a ser atendidos segundo o modelo convencional de tratar o desvio da normalidade em saúde, considerando o problema da fome relacionado a sintomas e suas manifestações clínicas. Lógico que não se pode desconhecer essa relação. Queremos ressaltar é que não podemos separar as condições de "saúde - doença" da pobreza, focalizando a atenção somente no tratamento clínico. Muitos profissionais envolvidos no tratamento da desnutrição reconhecem que os aspectos socioeconômicos e culturais da fome são tão importantes quanto as manifestações clínicas (Macdonald,1994).

$\mathrm{Na}$ realidade de nosso País, a fome atinge uma grande parcela do povo brasileiro, em conseqüência, a desnutrição torna-se a doença de milhões de crianças comprometendo acentuadamente os menores de cinco anos, por sua vulnerabilidade biológica e dependência socioeconômicos.

Para Batista Filho (1999), o consumo insuficiente de alimentos e a ocorrência freqüente de doenças evitáveis derivam da pobreza, como condição, e do subdesenvolvimento econômico e social, tendo como justificativa o próprio processo histórico. 0 baixo poder de compra das populações restringe o consumo familiar de energias e nutrientes. A pobreza é expressa nas condições insalubres das moradias, inadequação ou impossibilidade de acesso às ações básicas de saúde e desconhecimento, assim como, falta de conscientização das práticas de promoção e proteção contra as doenças evitáveis, que condiciona as taxas elevadas de morbidade infantil.

A desnutrição infantil é um problema restrito não só às áreas rurais, mas atinge também as grandes metrópoles, onde reinam elevados níveis de desigualdades sociais, produzindo assim, acentuada pobreza. No meio urbano, onde se situam os mercados consumidores dos produtos industrializados, a desnutrição infantil aparece como conseqüência do desmame precoce, influenciado pela ação mercadológica do aleitamento artificial, que invade os lares através da propaganda, conseguindo algumas vezes a inversão de valores culturais relacionados ao aleitamento materno, comprometendo ainda mais o estado nutricional da criança (Goldenberg, 1989).

Ressalta-se, ainda, que a cidade de Fortaleza, com o crescimento do êxodo rural, traz consigo as superlotações nas favelas, aumentando conseqüentemente a criminalidade, a prostituição e a violência, uma subvida conturbada, na qual o dia-a-dia se torna uma verdadeira luta pela sobrevivência. A criança desnutrida nesta ambiência torna-se suscetível a doenças e requer hospitalização mais freqüente e por períodos longos, levando a mãe adolescente a viver parte de sua vida dividida entre a casa e os serviços de saúde (F rota,1996).

Nas questões de saúde, a mãe é quem se mobiliza, desenvolvendo um papel fundamental em relação ao cuidado com o filho. A realidade vivenciada pelas mães que freqüentam o IPREDE indica que elas procuram fazer uso de plantas no tratamento da desnutrição, estando esse, na maioria das vezes, ligado ao saber empírico e atribuições de valores de cura da mãe.

A desnutrição do filho é também reflexo da saúde da mãe, ou seja, a condição de mães desnutridas reflete na saúde de seus filhos. Mães desnutridas não terão condições de amamentar seus filhos e esses serão também desnutridos.

0 risco de filhos de mães adolescentes nascerem com problemas é maior do que em mães adultas. Os mais comuns são baixo peso e os problemas respiratórios (Internet. Teenage Pregnancy: facts you shoud know.1998; p.2).

No Brasil, números oficiais do Ministério da Saúde demonstram que a gravidez nas meninas de 10 a 19 anos também vem aumentando a cada ano. Em 1995, o Sistema Único de Saúde registrou 28.282 partos de adolescentes de 10 a 14 anos e 661.330 partos na faixa etária de 15 a 19 anos (Rocha, 1998, p.42).

Recentes estatísticas têm mostrado um contínuo aumento da gravidez na adolescência, no mundo todo. Este aumento é importante, pois tanto mães adolescentes como seus filhos podem vir a apresentar problemas de saúde. Nos Estados Unidos, aproximadamente um milhão de adolescentes engravidam por ano e mais de 530 dão à luz (Internet. Teenage Pregnancy: facts you shoud know.1998; p.1).

No Ceará, segundo dados da Secretaria de Saúde (SESA), em 1997, 10\% da população tiveram filhos quando menores de 18 anos. A Maternidade-Escola Assis Chataubriand (MEAC) atende 1.200 casos de adolescentes grávidas por ano. As meninas entre 11 e 18 anos representam 15\% dos atendimentos dessa maternidade (Diário do Nordeste, 15.02.98). 
Estas estatísticas têm preocupado os estudiosos, que conhecem não só as causas deste problema como também suas conseqüências biológicas, psicológicas e sociais, tanto para a mãe como para seu filho.

É importante salientar que a preocupação para essas adolescentes e sua família não finaliza na gravidez, mas continua, quando se tem casos de desnutrição, acarretando consultas freqüentes, medicações e as inevitáveis internações e recidivas.

As adolescentes são, em sua maioria, inexperientes e nem sempre contam com o apoio psicológico do pai da criança ou da família. É comum terem a gravidez tumultuada, dificultando os cuidados com a gestação, com o parto e com o filho.

O cotidiano da mãe adolescente, muitas vezes, é caracterizado por dificuldades, como o preconceito na escola e, conseqüentemente, 0 abandono dos estudos, assim comprometendo a oportunidade de trabalho e com isso obrigando-a a uma dependência financeira da família e do companheiro.

Durante o acompanhamento de mães adolescentes aos filhos internados, chamava-me a atenção a carga de responsabilidade que estas assumiam em uma fase de transição da infância para a fase adulta, caracterizada por conflitos, mudança no corpo, necessidade de amigos, experiências sexuais, dentre outros. Diante de tantas transformações, a adolescente assume o árduo papel de ser mãe e, neste estudo, mãe de uma criança desnutrida.

Ao realizar um estudo nos prontuários dos filhos desnutridos de mães adolescentes, pudemos confirmar a relação entre a desnutrição e o baixo ou nenhum poder aquisitivo dessas famílias. Para a mãe adolescente, o fator econômico torna-se mais presente, por não possuir permissão para trabalhar, restando-lhe somente trabalhos que não exigem qualificação e que são considerados como exploração do menor. Frente a essa realidade, a mãe adolescente tende a permanecer em casa ociosa e, na maioria das vezes, assumindo toda a responsabilidade da casa, do cuidado dos irmãos menores e do próprio filho desnutrido.

Com base nessas reflexões, nosso objetivo foi descrever o cuidado à criança desnutrida filha de mãe adolescente.

\section{METODOLOGIA}

0 presente estudo é uma pesquisa qualitativa com enfoque etnográfico. As informantes foram 7 mães adolescentes que acompanharam seus filhos desnutridos internados no IPREDE - Instituto de Prevenção à Desnutrição e à Excepcionalidade. A partir da alta hospitalar, foi realizado acompanhamento no domicílio. 0 processo todo deu-se de agosto de 1997 a agosto de 1998. Foram selecionadas adolescentes de cuja família depende a manutenção própria e da criança.

A coleta e análise de dados foram realizadas seguindo o modelo de Leininger (1991) com algumas adaptações à nossa realidade. Seguiram-se as fases de observação, observação com participação, participação com observação e reflexão. A reflexão, é um momento de checar e confirmar os achados e está presente em todas as fases do processo de pesquisa.

\section{MÃE ADOLESCENTE NA FAMÍLIA}

$\mathrm{Na}$ busca de uma maior interação com as mães e, conseqüentemente, de sua confiança, no momento da observação, acompanhamos várias atividades (relaxamento, aula na farmácia-viva, pintura, atividades socioculturais) realizadas durante a semana para as mães que acompanhavam o filho desnutrido.

Algumas mães, quando chegavam à "sala azul", local reservado para sessões de relaxamento, ficavam inibidas, outras, pelo contrário aproveitavam para conversar. Nas sessões de relaxamento, as mães se deitavam em colchonetes, mas algumas preferiram deitar-se no chão, fechavam os olhos e ouviam as músicas orquestradas e de melodia tranqüila. Ao mesmo tempo, a instrutora dizia para respirarem profundamente e que procurassem ouvir o barulho das àrvores, do vento, depois conversavam sobre como cada uma se sentiu; uma mãe adolescente nesse momento relatou: eu gostei, por que as vezes eu tô em casa preocupada, agoniada, aí eu tomo um valium, quase todo dia, agora eu vou tentar fazer isso.

Pude observar que as mães adolescentes pouco ficavam nas enfermarias ao lado do berço da criança, permaneciam ao telefone público, o preferido delas, que havia na calçada da Instituição; faziam questão de 
acompanhar crianças que estavam sem as mães e que necessitavam sair para exames, ou, às vezes, andando em outros setores, ou na praça em frente ao IPREDE. Quando apareciam, olhavam o filho e saíam, andavam em grupo, principalmente quando faziam amizade umas com as outras, o que não era muito difícil. É válido ressaltar, a solidariedade e a confiança que surgiram entre elas. Às vezes, uma ficava cuidando da criança da outra, quando havia necessidade de irem à casa ver as tarefas domésticas, companheiro e outros filhos.

As mães participaram de uma aula na farmácia-viva, sobre como fazer chás e xaropes com plantas, raízes, cascas. Foi então possível durante as explicações e questionamentos perceber que as mães encontram os ensinamentos de tratamentos como estes, com os seus familiares. A mãe que me ensinou fazer chá de cebola que é bom pra dor de barriga. Não sei fazer, quando eles adoecem é meu pai que faz os chás. Algumas nem mesmo sabiam fazê-lo, deixando por conta dos avós essa responsabilidade.

A observação participante surgiu em conseqüência da interação, dando oportunidade à uma aproximação com as mães, quando foi possível participar no cuidado do filho desnutrido.

Conversando com as mães adolescentes, uma delas disse que o filho da outra tinha o bucho quebrado, enquanto a mãe da criança discordava fortemente. Desconhecendo tal mito, logo as mães procuraram explicar o significado. Bucho quebrado é quando a criança tem a barriga grande, mas os braços e as pernas são finas.

U ma mãe soprava desesperadamente o rosto do filho que tossia muito, fiel à crença de que: Assopro é bom para engasgo; outras mães que se encontravam perto concordaram fielmente, embora a criança não parasse de tossir.

É ainda marcante a presença da crença no "quebranto" e "mau-olhado". O imaginário popular cresce e, junto, as histórias vão surgindo: quem bota quebranto se ficar com raiva, não bota mais, mandava o pai rezar e ele dizia que era quebranto. Os mitos na maioria das vezes estavam enraizados na cultura familiar que se desenvolveu ao longo dos tempos e, é claro, tem o seu valor e deve ser respeitado.

Outro mito que surgiu e que muitas vezes predispõe à desnutrição da criança é a mãe acreditar que o leite materno é fraco, que amamentar deixa os seios caídos, que não tem leite e outros. Ocorrendo o desmame precoce e o início da alimentação artificial, surgem as diarréias freqüentes. Com isso, outra crença toma lugar: são os dentes que estão começando a aparecer, a justificativa confortando a mãe que parece não se dar conta da perda de peso do filho. 0 pessoal dizia que ela tava magrinha. Estas afirmações demonstram aparentemente uma fuga da realidade que é a desnutrição do filho, comprometendo ainda mais o estado da criança, podendo também ser uma questão de imaturidade da mãe que é ainda uma adolescente.

Participando e observando as mães no horário da alimentação, ajudando a dar o mingau ou a sopa das crianças que por um motivo ou outro as mães não estavam acompanhando, esse momento tornou-se de grande importância, pois foi possível observar a interação mãe-filho durante a refeição: algumas impacientes, outras triste porque o filho não aceitava o alimento, havendo também mãe desfilando satisfeita com o prato na mão, comentando que o filho tinha se alimentado bastante (F rota,1998).

O cuidar do filho é descrito por uma mãe adolescente pelo trabalho que representa o cuidado do filho. Tem gente que reclama que dá trabalho e só tem um, eu tenho duas. Abandonada pelo namorado quando estava grávida de gêmeos, encontrou apoio e ajuda nos familiares.

A mãe acredita que a solução da desnutrição do filho são as vitaminas ou alimentos como produto lácteo industrializado e outros de multinacionais que através dos anúncios, com investimentos altíssimos de propaganda, invadem os lares, seja qual for o nível socioeconômico, incentivando o consumo. A influência no comportamento da mãe é tão eficiente que ela vai catar lixo no aterro do J angurussu, onde é depositado o lixo da Cidade. A mãe não tem dúvida alguma que, ao dar o alimento, mesmo retirado do lixo, está fazendo o melhor para o filho. Na rampa do J angurussu eu pegava e dava pra ela. Minha vizinha me deu infectrim que era bom pra ela. Outra prática da mãe ao cuidar da recuperação do filho é o uso de vitaminas. Bom pra ela é complexo B gotas. Mesmo sem a mínima condição financeira, as mães fazem o possível para adquirir medicamentos caros. As mães também adquirem remédios com as vizinhas, entre as quais sempre aparece uma "super-entendida" que consulta, dá diagnóstico e prescreve o medicamento.

A difícil realidade econômica interfere no cuidar do filho. Segundo as mães, a falta de alimento leva o filho à desnutrição, enquanto para outras mães, a desnutrição é vista como sinônimo de diarréia. É algo comum que toda criança tem, é dos dentes que estão nascendo. Ainda na visão da mãe, a desnutrição da filha existe desde o nascimento, acreditando ser uma normalidade o baixo peso da criança até que alguém sugira: é melhor levar essa bichinha pra consulta, pode ela morrer. 
As mães observadas associam o cuidar bem à decisão de não deixar o filho sair para brincar. Talvez 0 sentimento de culpa seja incutido à mulher por haver exposto o filho ao ambiente externo: o pai cuida deles melhor do que eu, pois ele não deixa as crianças saírem e eu deixo.

É perceptível a necessidade de conscientização para o cuidar, pois o retrato da realidade que podemos ver são mães passivas aceitando o que é dito para o melhor cuidado do filho, porém fazendo exatamente o que acreditam ser o melhor e que muitas vezes não coincide com o que ouviram. É crucial, por conseguinte, a necessidade de um trabalho de educação transformadora para o cuidar, através de orientações que levem em consideração o contexto de vida de cada mãe, suas crenças e potencialidades.

\section{CONSIDERAÇÕES FINAIS}

O conhecimento empírico do cuidado é universal, diverso e está presente em todos os contexto culturais. Se pararmos um pouco para pensar em como cada um vê o cuidado, nos encontraríamos em meio a inúmeras crenças, valores e mitos não muito diferentes daqueles presentes nos relatos de mães adolescentes, ou seja, o cuidado está diretamente ligado à cultura de um povo. Torna-se importante, então, para a enfermagem procurar sempre conhecer a cultura do cliente, associando o conhecimento empírico ao saber científico.

É fundamental que o cuidado cultural seja respeitado, porém, se a maneira do cuidar realizado por mães aos seus filhos desnutridos estiver de alguma forma prejudicando a recuperação da criança, torna-se extremamente necessário que o profissional de saúde, utilizando-se de metodologia adequada na visão crítica e transformadora, reflita em grupos organizados com as mães, sobre o ato de cuidar e sua implicação para a promoção da saúde ou agravamento da doença ou da vulnerabilidade de crianças de mães adolescentes de baixo poder aquisitivo.

A participação de todos os profissionais de saúde pode contribuir para a reversão da desnutrição e suas conseqüências, através de programas preventivos no atendimento às famílias com filhos desnutridos. Um programa sistemático visando à prevenção ou controle de fatores de risco pode, com o decorrer dos anos, evidenciar a redução da mortalidade infantil.

Concluímos, reiterando a necessidade de estudos científicos que divulguem a eficácia do cuidado de enfermagem à criança desnutrida, quando esse cuidado envolve a cultura das famílias, provocando uma possível redução no índice de internamentos por desnutrição grave.

ABSTRACT: This study approaches the adolescent mother's of undernourished child family context being used the ethnographic method to contemplate on the cultural care accomplished by those mothers. It is noticed that the adolescent mothers accept of relatives and neighbors what is better for the care with the son. It is concluded by the need of an educational work that contextualize the care with undernourished child.

KEY WORDS: Nursing; Culture of the family; Undernourished child; Adolescent mother.

\section{REFERÊNCIAS BIBLIOGRÁFICAS}

1. Aumenta Taxa de Fecundidade entre adolescentes. In: J ornal Diário do Nordeste, Fortaleza, 15 Fev. 1993.

2. BATISTA FILHO, M. Alimentação, Nutrição e Saúde. In: ROUQUAYROL, M. Z., ALMEIDA FILHO, de N. Epidemiologia e saúde. 5. ed. Rio de J aneiro : MEDSI, 1999.

3. ELSEN, Ingrid. Saúde familiar: a trajetória de um grupo. In: BUB, Lydia I. R.(coordenadora); PENNA, Cláudia M.M. et al. Marcos para a prática de enfermagem com famílias. Florianópolis : Ed da UFSC, 1994.

4. FREIRE, Paulo. Pedagogia do oprimido. 17.ed. Rio de Janeiro : Paz e Terra, 1987.

5. FROTA, Mirna A. Desnutrição como fator que interfere no desenvolvimento organizacional da cultura familiar. Fortaleza, 1997. 30 p. Monografia (Especialização) - Universidade Federal do Ceará, 1997.

6. FROTA, Mirna. A. Como cuido do meu filho desnutrido: abordagem cultural. Fortaleza, 1998. Dissertação (Mestrado em Enfermagem) - Departamento de Enfermagem, Universidade Federal do Ceará, 1998.

7. GOLDE NBER G, Paulete. Repensando a desnutrição como questão social. 2. ed. São Paulo : Cortez; 1989.

8. LEININGER, Madeleine M. Culture care diversity and universality: a theory of nursing. New York : National League for Nursing, 1991.

9. MACDONALD, J ohm J. Primary health care: medicine in its place. London : Earthscan Publications, 1994.

10. ROCHA, A. Caderno do Terceiro Mundo, n.205, p.40-43, jan. 1998. 
